\title{
Uroplakins in the Lower Urinary Tract
}

\author{
Gilho Lee \\ Department of Urology, Dankook University College of Medicine, Cheonan, Korea
}

\begin{abstract}
The apical surface of mammalian urinary epithelium is covered by numerous scallop-shaped membrane plaques. This plaque consists of four different uroplakins (UPs) and integral membrane proteins. UPs, which are a member of the tetraspanin superfamily, are assembled into plaques that act as an exceptional barrier to water and toxic materials in urine. Within the plaques, the four UPs are organized into two heterodimers consisting of UP Ia/UP II and UP Ib/UP III in the endoplasmic reticulum. The two heterodimers bind to a heterotetramer, and then assemble into 16-nm particles in the Golgi apparatus. The aggregated UP complex ultimately covers almost all the mature fusiform vesicles in cytoplasm. These organelles migrate towards the apical urothelial cells, where they can fuse with the apical plasma membrane. As a result, the UPs are synthesized in large quantities only by terminally differentiated urothelial cells. For this reason, the UPs can be regarded as a major urothelial differentiation marker. In UP knockout (KO) mice, the incorporation of fully assembled UP plaques in cytoplasm into the apical surface is not functional. The mice with UP III-deficient urothelium show a significantly reduced number of UPs, whereas those with UP II-deficient urothelium have nearly undetectable levels of UPs. This finding strongly suggests that UP II ablation completely abolishes plaque formation. In addition, UP II KO mice contain abnormal epithelial polyps or complete epithelial occlusion in their ureters. UP IIIa KO mice are also associated with impairment of the urothelial permeability barrier and development of vesicoureteral reflux as well as a decrease in urothelial plaque size. In this review, I summarize recently published studies about UPs and attempt to explain the clinical significance of our laboratory results.
\end{abstract}

Keywords: Uroplakin; Urothelium; Animal model

Because the kidney filters plasma and excretes the wastes into the urine, urine differs markedly from plasma in osmolality and acidity. The urinary bladder in mammals stores highly permeable molecules such as urea, ammonia, and water to prevent them from crossing the bladder mucosa for prolonged periods without disturbance [1-3]. The mechanism of a permeable barrier has been suggested for these reasons. Sun et al. [3-7] reported that the apical membrane of urinary bladder contains a group of four related transmembrane (TM) proteins, called uroplakins (UPs), that act an exceptional barrier to water, small non-electrolytes, and protons. The asymmetric unit membrane (AUM), which can be seen by electron microscopy, forms the apical plaques of mammalian urothelium [3,8]. The AUM consists of the numerous assembly of four UPs: Ia, Ib, II, and III [4-7]. The UPs are believed to play a role in homeostasis in the urinary bladder mucosa during contraction and relaxation, preventing the AUM from rupturing during bladder distension [9-11].

When this permeability barrier is breached, irritants in the urine reach the bladder submucosa structure, musculature, and nociceptive nerve endings. The inflamed nociceptor fibers can ignite an abnormal sensory circuit and the injured muscular structures lead to urinary frequency, urgency, and painful voiding syndrome [12,13]. Furthermore, long-lasting breaches in the bladder permeability barrier may lead to dysplasia of tumor growth, interstitial cystitis, and non-bacterial chronic cystitis $[13,14]$.

Although extensive studies have been conducted over the past two decades on the pathophysiology of voiding dysfunction, little research has been carried out on the role of UPs in the urinary bladder. This review will summarize the genetic
Corresponding author: Gilho Lee

Department of Urology, Dankook University Hospital, Dankook University

College of Medicine, 16-5 Anseo-dong, Dongnam-gu, Cheonan 330-715, Korea

Tel: 82-41-550-6630 / Fax: 82-41-550-3905 / E-mail:prostate@ymail.com

Submitted: March 4, 2011 / Accepted after revision: March 20, 2011
This is an Open Access article distributed under the terms of the Creative Commons Attribution Non-Commercial License (http://creativecommons.org/licenses/by-nc/3.0/) which permits unrestricted non-commercial use, distribution, and reproduction in any medium, provided the original work is properly cited. 
characteristics and significance of UPs in the field of translational research.

\section{GENETIC CHARACTERISTICS OF UROPLAKINS}

The AUM contains four uroplakins: UP Ia, UP Ib, UP II, and UP III (UP IIIa and UP IIIb) (Fig. 1). The mammalian UPs, including bovine, human, and mouse, are highly conserved [15]. Many tetraspanins such as UP Ia and Ib interact with important single TM domain signaling partner proteins [16,17]. As can be inferred from the name, the tetraspanin superfamily contains four TM domains (Fig. 2) [17]. The tetraspanin superfamily usually contains several conserved amino acid residues in amino acid sequences, which suggests that these UPs may play important roles in cell migration, immunologic signaling, infec-
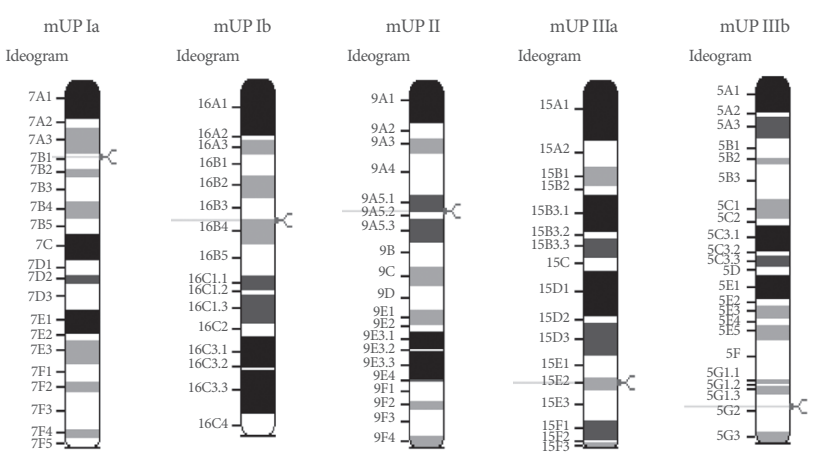

Fig. 1. The functional units of mouse uroplakins (UPs) are encoded by separate genes on different chromosomes. The mammalian UPs, including bovine, human, rat, and mouse, are highly conserved.

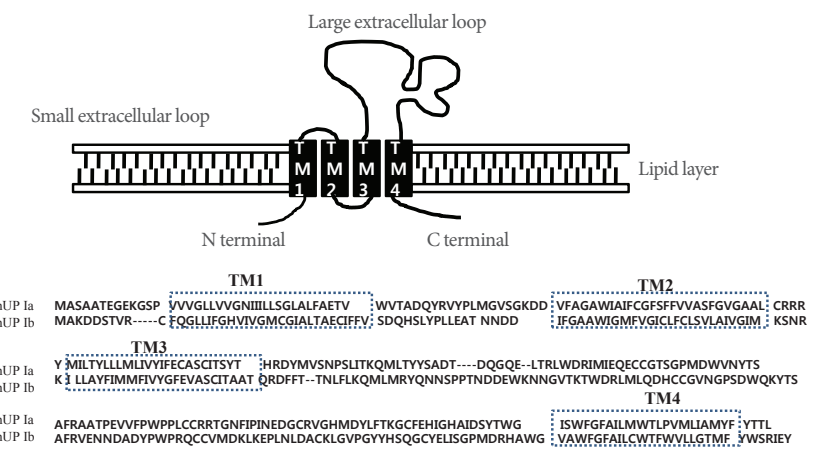

Fig. 2. Molecular structures of tetraspanins. Many tetraspanins such as uroplakin Ia, and Ib are typically composed of 4 transmembrane (TM) domains containing several conserved amino acid sequences (Modified from Levy S and Shoham T. Physiology (Bethesda) 2005;20:218-24, with permission American Physiological Society) [17]. tion, and membrane architecture $[18,19]$. However, UP II and UP III have only a single TM domain and share a stretch of 12 amino acid residues located on the extracellular side of the single TM domain (RT/SGGMV/IVITV/SL/IL) (Fig. 3) [20]. Of these four major UPs, UP IIIa is the only one that has a relatively large cytoplasmic domain of 50 amino acid residues, which has been postulated to play a role in interacting with the cytoskeleton (Fig. 3) [4,20,21].

The sequence of UP IIIb is related to that of UP IIIa, and they also have six similar exons and share conserved sequences such as IDTWPGRRSC/GMIVITSIL in the extracellular side of the TM domain, which suggests that the conserved area plays an active role for interacting with other important proteins (Fig. 4). UP II is synthesized as a pre (26 amino acids)-pro (59 amino acids)-mature protein (100 amino acids); the mature UP II (15$\mathrm{kDa}$ ) can be divided into a long extracellular domain of 71 amino acids and a TM domain of 25 amino acids, with almost no

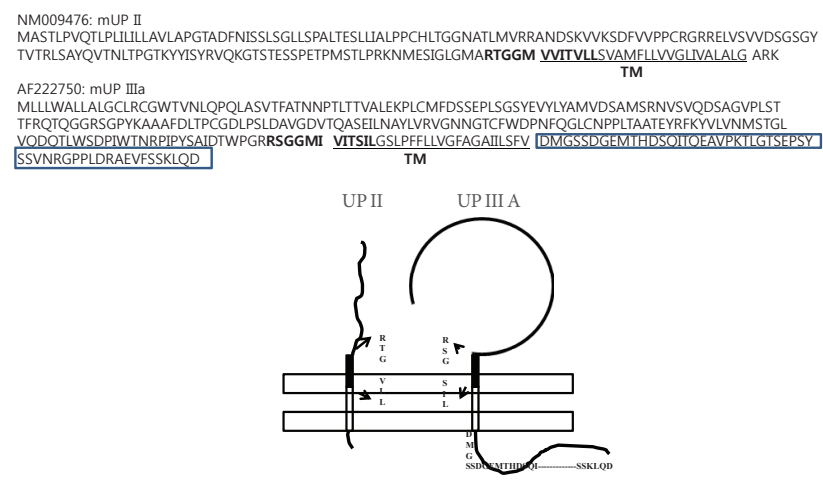

Fig. 3. The mouse uroplakin (UP) II and UP IIIa have a single transmembrane (TM) domain and share a conserved 12 amino acid residues located on the extracellular side and the TM domain (RT/SGGMV/IVITV/SL/IL). Interestingly, UP IIIa is the only UP that has a relatively large cytoplasmic domain of 50 amino acid residues. (Modified from Sun TT. Am J Physiol Renal Physiol 2006;291:F9-21, with permission of American Physiological Society) [20].

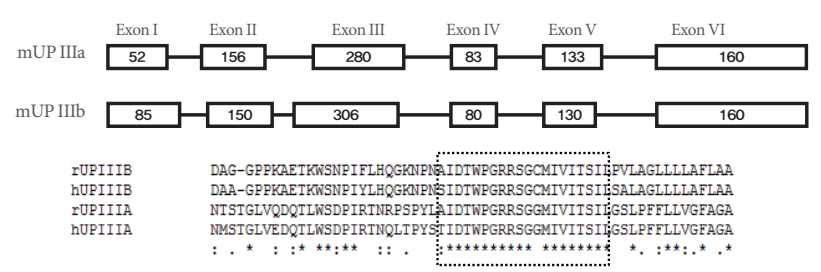

Fig. 4. The mouse uroplakin IIIa and IIIb have 6 exonal structures. The amino acid residues from rat and human uroplakin IIIa and IIIb also share conserved amino acid sequences. 

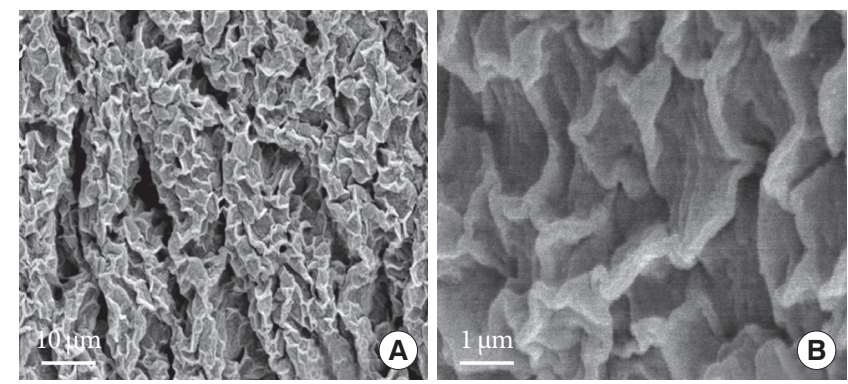

Fig. 5. Scanning electron microscopic images of normal mouse urinary bladder. The mouse urinary bladder epithelium is covered by numerous scallop-shaped membrane plaques.

intracellular domain [4]. UP IIIa is synthesized as a pre-protein; the mature protein $(47-\mathrm{kDa})$ contains an apoprotein of $29-\mathrm{kDa}$ plus 18-kDa equivalents of complex glycans [21].

\section{MORPHOLOGY OF UPS}

The structure of the urothelial plaque has been studied by using a number of ultrastructural techniques, including atomic force microscopy, quick-freeze deep-etch, and cryo-electron microscopy $[8,22,23]$. Such data have shown that the apical surface of the mammalian urinary bladder epithelium is covered by numerous scallop-shaped membrane plaques (Fig. 5). The plaque has a unique structure in which its outer leaflet is about twice as thick as the inner one, hence, the name asymmetric unit membrane [24]. The AUM contains four different UPs and integral membrane proteins that assemble into hexagonal plaque particles [20].

Within each UP pair (UP Ia/II and UP Ib/IIIa), there are a total of five TM domains (four TMs for UP Ia and UP Ib, and one TM for UP II and UP III) [25,26]. The five TM helices of each heterodimer are tightly packed, forming six inner-domains and six outer-domains. Furthermore, UPs stabilize a particularly rigid set of lipids within the outer leaflet in the AUM [22].

The AUM structure is also present in fusiform-shaped cytoplasmic vesicles representing a pre-apical membrane compartment. These fusiform-shaped cytoplasmic vesicles create a concave or scallop-shaped plaque in the apical membrane or in terminally differentiated urothelial (umbrella) cells [11,20,27].

\section{FUNCTIONS OF UPS}

The amino acid sequences of mammalian UPs are highly conserved, which suggests that they play an essential function in

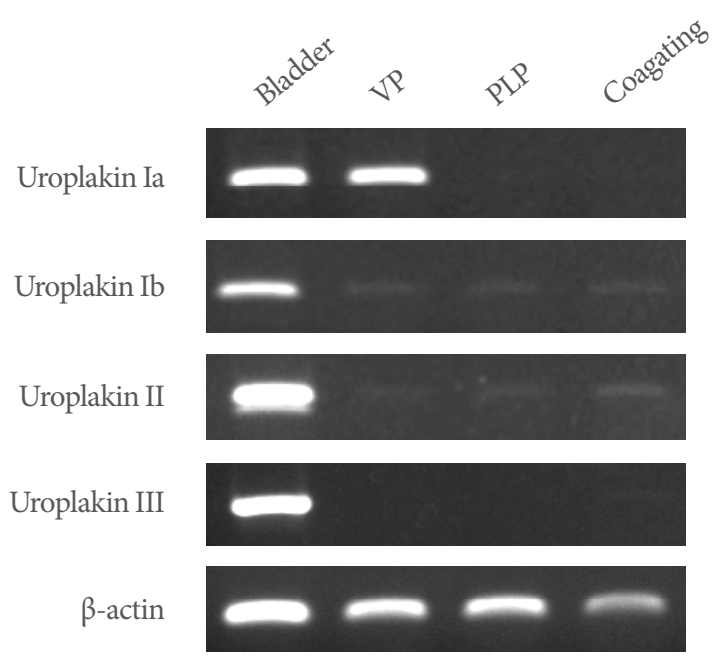

Fig. 6. Uroplakin and $\beta$-actin expression on urinary bladder and prostate. Bladder, urinary bladder; VP, ventral prostate; PLP, posterior lateral prostate; Coagulating, coagulating gland (Reprinted from Lee DH and Lee GH. Korean J Androl 2010;28: 112-7, with permission of Korean Society for Sexual Medicine and Andrology) [31].

urinary bladder epithelium $[1,2,15,16]$. This highly specialized membrane is believed to serve as an exceptionally effective permeability barrier [1-3], as a mechanical anchorage site mediating binding of the cytoskeleton to the apical membrane surface $[8,5]$, and as a mechanism for adjusting the apical surface area through the reversible insertion and retrieval of the apical plaques $[10,11,27,28]$. Furthermore, urothelial plaques are biochemically unique. These membranes are unusually stable in that they remain insoluble in a number of harsh conditions including $2 \%$ NP-40, 2\% sodium sarcosine, $25 \mathrm{mM} \mathrm{NaOH}, 9 \mathrm{M}$ urea, and 6 M guanidiumchloride [2].

In normal urothelium, differentiated superficial cells gradually develop from basal and intermediate cells. Because urothelial plaques and their protein subunits, i.e., the UPs, are synthesized in large quantities only by terminally differentiated urothelial cells, the UPs are regarded as a major urothelial differentiation marker [29]. In addition, recent studies indicate that UP Ia may serve as the urothelial receptor for type 1-fimbriated Escherichia coli, which causes $90 \%$ of urinary tract infections [30]. UP Ia is only expressed in mouse ventral prostate. This suggests that the mouse ventral prostate may be an adequate locus for acute or chronic bacterial prostatitis study (Fig. 6) [31].

The presence of UP Ib in the ocular surface and respiratory epithelia suggests that UP Ib may play a unique biological role in these tissues (Table 1). 
Table 1. Uroplakin mRNA expression in various tissues from expressed sequence tag (EST)

\begin{tabular}{|c|c|c|c|}
\hline Gene & $\begin{array}{l}\text { Genbank } \\
\text { code }\end{array}$ & Code type & $\begin{array}{l}\text { Characteristics of EST } \\
\text { expression }\end{array}$ \\
\hline \multirow[t]{7}{*}{ Uroplakin Ia } & NM026815.2 & $\begin{array}{l}\text { Reference } \\
\text { RNA }\end{array}$ & Urinary bladder \\
\hline & DV043876 & EST & $\begin{array}{l}\text { Prostate pool, } \\
10 \text { day old male mice }\end{array}$ \\
\hline & DV048517 & EST & $\begin{array}{l}\text { Prostate pool, } \\
35 \text { day old male mice }\end{array}$ \\
\hline & BX517024 & EST & Uterus, adult \\
\hline & AI225453 & EST & Uterus, adult \\
\hline & DV074433 & EST & Prostate, ventral prostate \\
\hline & DV074432 & EST & Prostate, ventral prostate \\
\hline \multirow[t]{13}{*}{ Uroplakin Ib } & NM178924 & $\begin{array}{l}\text { Reference } \\
\text { RNA }\end{array}$ & Urinary bladder \\
\hline & BQ892200 & EST & Olfactory epithelium \\
\hline & CF586524 & EST & Pancreas \\
\hline & BB653177 & EST & Hippocampus, adult mice \\
\hline & СК627789 & EST & Whole eye \\
\hline & BB530943 & EST & Lung, neonate \\
\hline & DV068933 & EST & $\begin{array}{l}\text { Prostate (pooled } \\
\text { urogenital sinuses) }\end{array}$ \\
\hline & DV552492 & EST & Total cornea, adult \\
\hline & CK922053 & EST & Thyroid \\
\hline & BB665799 & EST & $\begin{array}{l}\text { Oviduct, } \\
2 \text { days pregnant mice }\end{array}$ \\
\hline & CF586523 & EST & Pancreas \\
\hline & BY367830 & EST & Spleen, neonate \\
\hline & BB219662 & EST & Aorta and vein, adult male \\
\hline \multirow[t]{2}{*}{ Uroplakin II } & NM009476 & $\begin{array}{l}\text { Reference } \\
\text { RNA }\end{array}$ & Urinary bladder \\
\hline & CX565093 & EST & Whole eye \\
\hline \multirow[t]{4}{*}{ Uroplakin III } & AF222750 & $\begin{array}{l}\text { Reference } \\
\text { RNA }\end{array}$ & Urinary bladder \\
\hline & CB598360 & EST & Lung and heart \\
\hline & BX512009 & EST & Mammary gland \\
\hline & BB605052 & EST & Lung, neonate \\
\hline
\end{tabular}

\section{TRAFFICKING}

The mechanisms underlying the dynamic changes in the apical membrane compartment are unclear. Discoid vesicles may provide the bladder with a large membrane reserve to adapt to changes in urine volume and to immediately substitute leaky membrane areas. Fusion of the discoid vesicles with the apical plasma membrane results in an increase in the surface membrane area, which might be useful during filling of the bladder when the urothelium has to stretch $[11,20,32,33]$.

The UPs undergo an assembly process that begins in the endoplasmic reticulum (ER) where they form specific heterodimers $[20,25,26,34]$. Recent studies indicate that UP Ia and UP Ib bind to UP II and UP IIIa, respectively, forming the heterodimers Ia/II and Ib/IIIa before they can exit from the ER $[16,26$, 34]. UP Ib is exceptional because it can exit, by itself, from the ER [26].

Severs and Hicks [35] have shown that, in normal urothelium, 16-nm particles can be detected in early vesicles that have just budded off the Golgi apparatus, which suggests that the two UP heterodimers (Ia/II and Ib/III) interact before they leave the Golgi apparatus to form the 16-nm particle. These data suggest that UPs first form heterodimers in the ER [26], and possibly heterotetramers; the heterotetramers then assemble into the 16-nm particles in the Golgi apparatus or the trans-Golgi network. Then, these particles, once reaching a sufficient density in the post-Golgi vesicles, aggregate to form small, and later, large $2 \mathrm{D}$ crystals. In a post-Golgi compartment they form increasingly larger crystalline arrays $[8,28]$, which ultimately cover almost the entire surface of the mature fusiform vesicles. These organelles migrate toward the apical cell periphery where they can fuse with the apical plasma membrane $[10,32,33]$.

Although UP Ia is transported to the plasma membrane only after heterodimerization with UPII, UP Ib is unique in that it can exit from the ER and move to the plasma membrane even when expressed by itself at the surface of urothelial cells of UP IIIa-knockout (KO) mice [26]. On the other hand, in UP II-KO mice, UP Ia remains trapped in the ER [9].

\section{UP EXPRESSION IN CELL LINES}

Cultured urothelial cells can synthesize the UPs, but the UPs do not assemble into two-dimensional crystals [36]. Thus, cultured bovine urothelial cells still synthesize large amounts of the UPs, although they almost completely lack the cytoplasmic (fusiform) vesicles that are prominent cellular structures in mature umbrella cells in vivo and which are presumably involved in delivering the UPs to the apical surface [36,37]. Moreover, the apical surface of these cultured urothelial cells completely lack the two-dimensional crystals of $16 \mathrm{~nm}$ uroplakin particles [20,36, 37]. The inability of regenerating urothelial cells to assemble 
Table 2. Expression of uroplakin transcripts by normal and tumor-derived urothelial cell lines by ribonuclease protection as-

\begin{tabular}{lcccccc}
\hline Cell line & Pathology & Origin & UP Ia & UP Ib & UP II & UP III \\
\hline RT4 & Papilloma & $\begin{array}{c}\text { Urinary } \\
\text { bladder }\end{array}$ & $2+$ & $3+$ & $3+$ & $2+$ \\
RT112 & Carcinoma & $\begin{array}{c}\text { Urinary } \\
\text { bladder }\end{array}$ & N & $3+$ & N & N \\
HT1376 & Carcinoma & $\begin{array}{c}\text { Urinary } \\
\text { bladder }\end{array}$ & N & $3+$ & N & N \\
Colo232 & Carcinoma & $\begin{array}{c}\text { Urinary } \\
\text { bladder }\end{array}$ & N & N & N & N \\
KK47 & Carcinoma & $\begin{array}{c}\text { Urinary } \\
\text { bladder }\end{array}$ & N & N & N & N \\
VM-CUB-3 & Carcinoma & $\begin{array}{c}\text { Urinary } \\
\text { bladder }\end{array}$ & $2+$ & $3+$ & $2+$ & N \\
\hline
\end{tabular}

$\mathrm{N}$, negative expression.

plaques could be functionally important, because a cell surface laden with the rigid-looking plaques may be incompatible with cell migration and proliferation during wound repair [20]. The RT4 cell line, derived from a grade 1 transitional cell carcinoma (TCC), can form a well differentiated stratified urothelium when seeded onto a stroma. This suggests that the RT4 cell line will be invaluable as a model for urothelial cytodifferentiation and for studying the differential regulation and expression of the UP genes. The expression of the UP Ia and UP II genes remains highly differentiation restricted in superficial TCC. The genes are expressed by the luminal cells of well-differentiated papillae, but the expression is lost from histologically less differentiated areas (Table 2) [38].

\section{KNOCKOUT MICE}

$\mathrm{KO}$ mice are genetically engineered mice in which a target gene or genes have been turned off through a targeted mutational method. For this reason, the UP KO mice are important animal models for studying the roles of UP genes. With KO mice of UP II or III, the incorporation of fully assembled UP proteins into the apical surface through fusion of the fusiform vesicles with the apical membrane was shown to play a role in the maintenance of the urothelial barriers [9,39].

In UP II KO mice, protein levels of UP Ia, UP Ib, and UP III are reduced 10-20-fold compared with those of the normal control mice. However, the mRNA levels of UP Ia and UP III are up-regulated twofold, whereas that of UP Ib is up-regulated by $10-20$-fold in a compensatory manner [9]. In addition, the UP-delivering fusiform vesicles are totally replaced by numerous small, spherical vesicles [9]. In UP II-deficient urothelium, although the UP Ib/III pair can be delivered to the apical surface and the small vesicles (150-200 nm in diameter) accumulate in the UP II-deficient superficial cells, the UP Ib/ III pair by itself cannot form the 16-nm particle, let alone the urothelial plaques. This leads to the entrapment of UP Ia in the ER, but allows the remaining UP Ib/III pair to reach the apical urothelial surface [9]. No 16-nm particle or apical plaques are formed. Some breeding pairs of UP II-deficient mice reproducibly die 8 to 10 days postnatally as a result of renal failure. It seems that major UP defects may cause urinary tract anomalies that, in severe cases, could lead to death. In addition, the levels of many urinary components, including uric acid, creatinine, potassium, sodium, and chloride ions, were slightly reduced, possibly because of defects in mechanisms of urine concentration in UP II $\mathrm{KO}$ mice. The concentration of blood urea nitrogen also almost doubled, suggesting a compromised renal function [9].

These results highlight the critical functional importance of UPs in the formation of a specialized urothelial apical surface. Serial sectioning of the urinary tracts from surviving UP II knockout mice reveal areas of the ureter with epithelial polyps or complete epithelial occlusion, which causes structural obstruction [9]. In addition, increased bladder capacity, micturition pressure, and demonstrable nonvoiding contractions are observed in male UP II KO mice compared with normal mice [40].

The detergent-insoluble membrane fraction of the UP IIIdeficient mouse urothelium shows a significantly reduced number of UPs, whereas that of the UP II-deficient urothelium contains almost no detectable UPs. Together, these results indicate that UP II ablation completely abolishes plaque formation. Because both heterodimers (Ia/II and Ib/IIIa) are required for normal plaque formation, it has been postulated that UP IIIb replaces the necessary function of the UP IIIa to form the Ib/ IIIb heterodimer, allowing for the small crystal plaques to develop. Again, knockout of UP II, which does not have a known isoform, leads to the complete absence of plaque formation, supporting the idea that the two UP heterodimers are both critical for plaque formation [9].

In the ablation of UP III, abnormal synthesis and processing of UP Ib, i.e., the level of UP Ib mRNA is greatly increased, whereas the amount of UP Ib protein is reduced [39]. These mice also have a reduced urothelial plaque size, compromised 


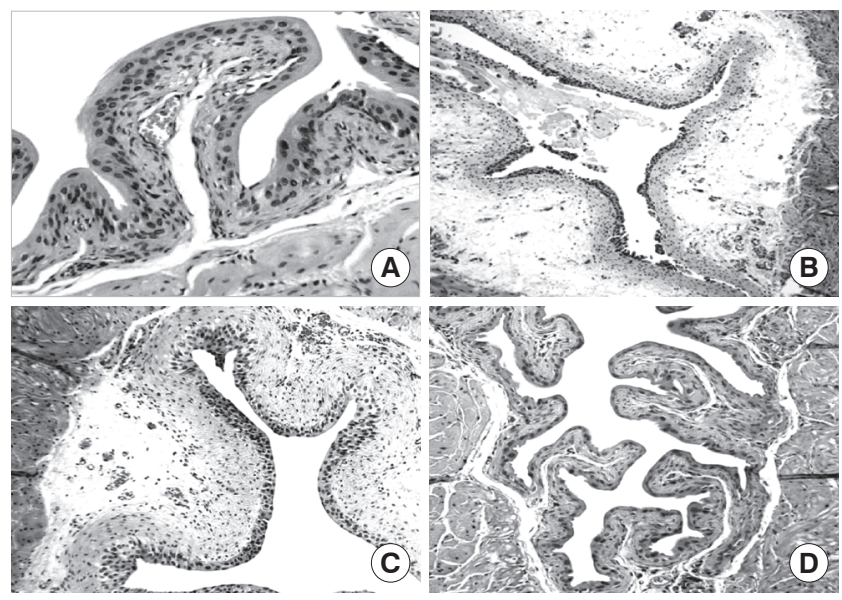

Fig. 7. Histological alterations in the cyclophosphamide-induced rat bladder. (A) normal epithelium projected to bladder lumen in controls $(\mathrm{H} \& \mathrm{E}, \times 40)$. (B) histologic section of the urinary bladder of mice showing epithelial ulceration, hemorrhage, and submucosal edema at 12 hours after cyclophosphamide injection $(\mathrm{H} \& \mathrm{E}, \times 10) .(\mathrm{C})$ and $(\mathrm{D})$, cystitis improved at 24 and 72 hours, respectively $(\mathrm{H} \& \mathrm{E}, \times 10)$ (Reprinted from Choi SH et al. J Korean Med Sci 2009;24:684-9, with permission of Korean Academy of Medical Sciences) [43].

urothelial permeability barrier function, and retrograde flow of urine from the bladder into the ureters (vesicoureteral reflux), resulting in hydronephrosis $[3,39]$. These results establish that UP III is an integral subunit of urothelial plaques, which contribute to the permeability barrier function of the urothelial apical surface, and suggest that urothelial defects may play a role in vesicoureteral reflux (VUR) [3,39]. The inactivation of the mouse UP III gene results in VUR and hydronephrosis raises the possibility that UP defects may cause VUR in humans $[39,41]$.

The spontaneous bladder contraction activity value for all male and female UP KO mice is significantly greater than that observed in the wild-type mice [40]. Furthermore, the UP II KO mice display significant elevations in spontaneous activity, intermicturition pressure, and micturition pressure relative to both the wild-type and UP IIIa KO mice [40]. The UP IIIa KO mice, in turn, have lower basal pressure and threshold pressure values than do either the UP II or wild-type mice [40]. Cystometric records from both UP II and UP IIIa KO mice (both males and females) reveal demonstrable nonvoiding contractions (i.e., detrusor overactivity ) [40]. Interestingly, the observed detrusor overactivity is more pronounced in the UP II KO mice than in the UP IIIa KO mice [40].

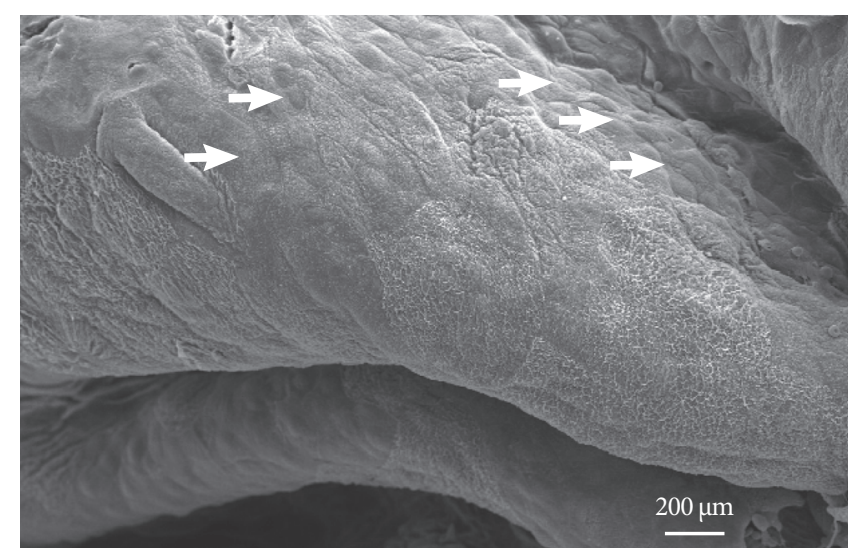

Fig. 8. Structural analysis of rat urothelium after 24-hour exposure to $150 \mathrm{mg}$ cyclophosphamide. There are clear-cut areas that are denuded of umbrella cells and intermediate cells can be discerned. Arrows indicate denuded areas.

\section{CHANGES IN UP EXPRESSION IN THE URINARY BLADDER AFTER CYCLOPHOSPHAMIDE TREATMENT}

The turn-over and differentiation of urothelial cells in the normal urothelium is very slow, and their life span is very long making it difficult to study the detailed sequence of differentiation stages in normal urothelium [42]. However, the turn-over or repair process in the urothelium after chemical insult is very rapid. This dynamic process can help us to understand the pathophysiological mechanisms of the UPs in the urinary bladder. In addition, because chemicals such as cyclophosphamide are well known to induce interstitial cystitis and hemorrhagic cystitis in animal models, it is a highly reasonable approach to determine the role of UPs in the urothelium by applying the cyclophosphamide-induced animal model.

Cyclophosphamide causes mucosal ulceration, transmural edema and epithelial necrosis that are associated with acute hemorrhage (Fig. 7) [43,44]. At 24 hours after cyclophosphamide exposure, the superficial epithelium is detached and intermediate cells are exposed (Fig. 8). The regeneration process is started immediately and is completed within 2 weeks after cyclophosphamide injection [27]. Various stages of urothelial differentiation accompany the regeneration. This is reflected in the successive appearance of microvilli and ropy ridges on the apical surface of the superficial cells [27]. The level of all UP mRNAs, the protein expression of UP II and IIIa by immunoblotting study, and the expression of UP IIIa by immunolocalization study are maximally suppressed within 12 hours; this par- 


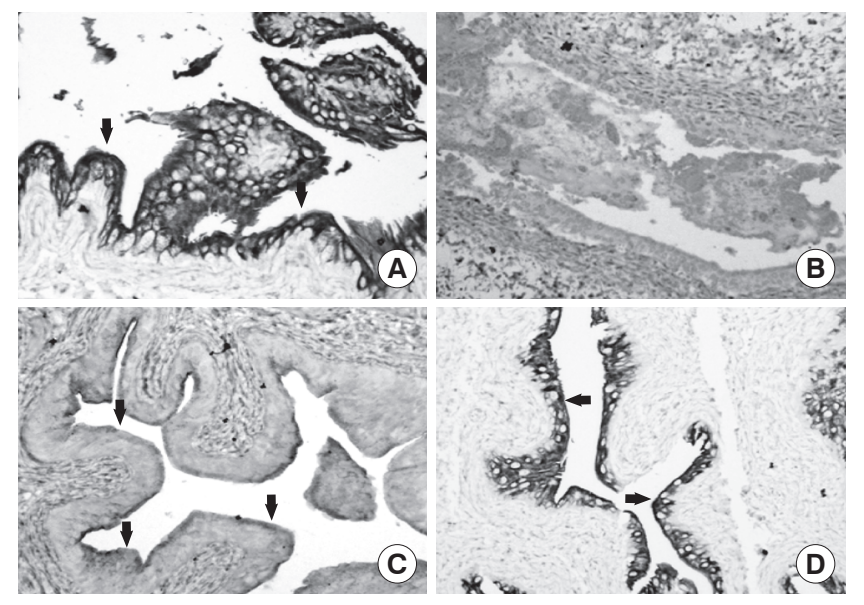

Fig. 9. Immunohistochemical reaction with anti-uroplakin III antibody. (A) Strong uroplakin III expression appeared along the bladder epithelium in control bladder. (B) At 12 hours after cyclophosphamide injection, there was a significant decrease or loss of uroplakin III expression in intact bladder mucosa (arrows). (C, D) Expression was weakly restored at 24 hours and completely recovered at 72 hours. All original magnifications were $\times 10$.

tially recovers at 24 hours and completely recovers at 72 hours following cyclophosphamide injection in the mouse bladder. Even though a large area of urothelium is lost after cyclophosphamide injection, some focal areas of intact uroepithelium show a significant reduction of UP III expression on immunohistochemical staining. It seems that cyclophosphamide may actively depress the expression of UPs in uroepithelium when they are damaged by cyclophosphamide (Fig. 9) [43]. These results suggest that rapid resealing of injuries to the bladder permeability barrier is of major physiological importance for restoring the protection ability of the bladder.

Vigorous diuresis and agents that can detoxify cyclophosphamide, such as 2-mercaptoethene sulfate (MESNA), have been used to decrease urotoxicity [44]. However, MESNA-treated rats reveal transient and early reductions in the mRNA levels of all UPs [44]. That finding suggests that MESNA treatment may partially preserve the UP expression of mRNA and protein in cyclophosphamide-induced urinary bladder epithelium. In addition, the responses in the level of UPs against cyclophosphamide insult are heterogeneous (i.e., markedly suppressed in UP II and lesser destructive in UP III) [44]. These findings can explain the fact that the bladder protection is not always achieved even after the prophylactic use of MESNA.

In conclusion, significant progress has been made in the characterizations of UPs in genitourinary tract diseases. As a result, it is generally accepted that UPs are actively involved in creating the blood-urine barrier and in urothelial differentiation, trafficking, and genitourinary development in animal models. Lessons from this basic research can lead to an understanding of the clinical significance of the UPs. Urothelial damage and vesical dysfunction in humans can be caused by interstitial cystitis, bladder outlet obstruction, and overactive bladder, as well as vesicoureteral reflux and kidney development. Studies of UPs expression and major UP genetic mutations can explain or help in our understanding of the mechanisms of the above lower urinary tract diseases. In the near future, some pharmacotherapies involving UPs may lead to large clinical benefits in the treatment of genito-urinary diseases.

\section{CONFLICT OF INTEREST}

No potential conflict of interest relevant to this article was reported.

\section{REFERENCES}

1. Zeidel ML. Low permeabilities of apical membranes of barrier epithelia: what makes watertight membranes watertight? Am J Physiol 1996;271(2 Pt 2):F243-5.

2. Negrete HO, Lavelle JP, Berg J, Lewis SA, Zeidel ML. Permeability properties of the intact mammalian bladder epithelium. Am J Physiol 1996;271(4 Pt 2):F886-94.

3. Hu P, Meyers S, Liang FX, Deng FM, Kachar B, Zeidel ML, et al. Role of membrane proteins in permeability barrier function: uroplakin ablation elevates urothelial permeability. Am J Physiol Renal Physiol 2002;283:F1200-7.

4. Lin JH, Wu XR, Kreibich G, Sun TT. Precursor sequence, processing, and urothelium-specific expression of a major 15-kDa protein subunit of asymmetric unit membrane. J Biol Chem 1994;269: 1775-84.

5. Wu XR, Manabe M, Yu J, Sun TT. Large scale purification and immunolocalization of bovine uroplakins I, II, and III. Molecular markers of urothelial differentiation. J Biol Chem 1990;265:19170-9.

6. Yu J, Lin JH, Wu XR, Sun TT. Uroplakins Ia and Ib, two major differentiation products of bladder epithelium, belong to a family of four transmembrane domain (4TM) proteins. J Cell Biol 1994;125: 171-82.

7. Yu J, Manabe M, Wu XR, Xu C, Surya B, Sun TT. Uroplakin I: a 27$\mathrm{kD}$ protein associated with the asymmetric unit membrane of mammalian urothelium. J Cell Biol 1990;111:1207-16. 
8. Kachar B, Liang F, Lins U, Ding M, Wu XR, Stoffler D, et al. Threedimensional analysis of the $16 \mathrm{~nm}$ urothelial plaque particle: luminal surface exposure, preferential head-to-head interaction, and hinge formation. J Mol Biol 1999;285:595-608.

9. Kong XT, Deng FM, Hu P, Liang FX, Zhou G, Auerbach AB, et al. Roles of uroplakins in plaque formation, umbrella cell enlargement, and urinary tract diseases. J Cell Biol 2004;167:1195-204.

10. Born M, Pahner I, Ahnert-Hilger G, Jöns T. The maintenance of the permeability barrier of bladder facet cells requires a continuous fusion of discoid vesicles with the apical plasma membrane. Eur J Cell Biol 2003;82:343-50.

11. Lewis SA. Everything you wanted to know about the bladder epithelium but were afraid to ask. Am J Physiol Renal Physiol 2000; 278:F867-74.

12. Lavelle JP, Apodaca G, Meyers SA, Ruiz WG, Zeidel ML. Disruption of guinea pig urinary bladder permeability barrier in noninfectious cystitis. Am J Physiol 1998;274(1 Pt 2):F205-14.

13. Lavelle JP, Meyers SA, Ruiz WG, Buffington CA, Zeidel ML, Apodaca G. Urothelial pathophysiological changes in feline interstitial cystitis: a human model. Am J Physiol Renal Physiol 2000;278: F540-53.

14. Lewis SA, Berg JR, Kleine TJ. Modulation of epithelial permeability by extracellular macromolecules. Physiol Rev 1995;75:561-89.

15. Wu XR, Lin JH, Walz T, Häner M, Yu J, Aebi U, et al. Mammalian uroplakins. A group of highly conserved urothelial differentiationrelated membrane proteins. J Biol Chem 1994;269:13716-24.

16. Hu CC, Liang FX, Zhou G, Tu L, Tang CH, Zhou J, et al. Assembly of urothelial plaques: tetraspanin function in membrane protein trafficking. Mol Biol Cell 2005;16:3937-50.

17. Levy S, Shoham T. Protein-protein interactions in the tetraspanin web. Physiology (Bethesda) 2005;20:218-24.

18. Hemler ME. Tetraspanin proteins mediate cellular penetration, invasion, and fusion events and define a novel type of membrane microdomain. Annu Rev Cell Dev Biol 2003;19:397-422.

19. Levy S, Shoham T. The tetraspanin web modulates immune-signalling complexes. Nat Rev Immunol 2005;5:136-48.

20. Sun TT. Altered phenotype of cultured urothelial and other stratified epithelial cells: implications for wound healing. Am J Physiol Renal Physiol 2006;291:F9-21.

21. Wu XR, Sun TT. Molecular cloning of a $47 \mathrm{kDa}$ tissue-specific and differentiation-dependent urothelial cell surface glycoprotein. J Cell Sci 1993;106( Pt 1):31-43.

22. Min G, Zhou G, Schapira M, Sun TT, Kong XP. Structural basis of urothelial permeability barrier function as revealed by Cryo-EM studies of the $16 \mathrm{~nm}$ uroplakin particle. J Cell Sci 2003;116(Pt 20):
4087-94.

23. Walz T, Häner M, Wu XR, Henn C, Engel A, Sun TT, et al. Towards the molecular architecture of the asymmetric unit membrane of the mammalian urinary bladder epithelium: a closed "twisted ribbon" structure. J Mol Biol 1995;248:887-900.

24. Hicks RM. The function of the golgi complex in transitional epithelium. Synthesis of the thick cell membrane. J Cell Biol 1966;30: 623-43.

25. Liang FX, Riedel I, Deng FM, Zhou G, Xu C, Wu XR, et al. Organization of uroplakin subunits: transmembrane topology, pair formation and plaque composition. Biochem J 2001;355(Pt 1):13-8.

26. Tu L, Sun TT, Kreibich G. Specific heterodimer formation is a prerequisite for uroplakins to exit from the endoplasmic reticulum. Mol Biol Cell 2002;13:4221-30.

27. Veranic P, Romih R, Jezernik K. What determines differentiation of urothelial umbrella cells? Eur J Cell Biol 2004;83:27-34.

28. Staehelin LA, Chlapowski FJ, Bonneville MA. Lumenal plasma membrane of the urinary bladder. I. Three-dimensional reconstruction from freeze-etch images. J Cell Biol 1972;53:73-91.

29. Sun TT, Zhao H, Provet J, Aebi U, Wu XR. Formation of asymmetric unit membrane during urothelial differentiation. Mol Biol Rep 1996;23:3-11.

30. Martinez JJ, Mulvey MA, Schilling JD, Pinkner JS, Hultgren SJ. Type 1 pilus-mediated bacterial invasion of bladder epithelial cells. ЕМВО J 2000;19:2803-12.

31. Lee DH, Lee GH. Uroplakin mRNA expression in the micro-dissected mouse prostate. Korean J Androl 2010;28:112-7.

32. Kreft ME, Jezernik K, Kreft M, Romih R. Apical plasma membrane traffic in superficial cells of bladder urothelium. Ann N Y Acad Sci 2009;1152:18-29.

33. Apodaca G. The uroepithelium: not just a passive barrier. Traffic 2004;5:117-28.

34. Wu XR, Medina JJ, Sun TT. Selective interactions of UPIa and UPIb, two members of the transmembrane 4 superfamily, with distinct single transmembrane-domained proteins in differentiated urothelial cells. J Biol Chem 1995;270:29752-9.

35. Severs NJ, Hicks RM. Analysis of membrane structure in the transitional epithelium of rat urinary bladder. 2 . The discoidal vesicles and Golgi apparatus: their role in luminal membrane biogenesis. J Ultrastruct Res 1979;69:279-96.

36. Truschel ST, Ruiz WG, Shulman T, Pilewski J, Sun TT, Zeidel ML, et al. Primary uroepithelial cultures. A model system to analyze umbrella cell barrier function. J Biol Chem 1999;274:15020-9.

37. Surya B, Yu J, Manabe M, Sun TT. Assessing the differentiation state of cultured bovine urothelial cells: elevated synthesis of strati- 
fication-related $\mathrm{K} 5$ and $\mathrm{K} 6$ keratins and persistent expression of uroplakin I. J Cell Sci 1990;97(Pt 3):419-32.

38. Lobban ED, Smith BA, Hall GD, Harnden P, Roberts P, Selby PJ, et al. Uroplakin gene expression by normal and neoplastic human urothelium. Am J Pathol 1998;153:1957-67.

39. Hu P, Deng FM, Liang FX, Hu CM, Auerbach AB, Shapiro E, et al. Ablation of uroplakin III gene results in small urothelial plaques, urothelial leakage, and vesicoureteral reflux. J Cell Biol 2000;151: 961-72.

40. Aboushwareb T, Zhou G, Deng FM, Turner C, Andersson KE, Tar $\mathrm{M}$, et al. Alterations in bladder function associated with urothelial defects in uroplakin II and IIla knockout mice. Neurourol Urodyn
2009;28:1028-33.

41. Mak RH, Kuo HJ. Primary ureteral reflux: emerging insights from molecular and genetic studies. Curr Opin Pediatr 2003;15:181-5.

42. Hicks RM. The mammalian urinary bladder: an accommodating organ. Biol Rev Camb Philos Soc 1975;50:215-46.

43. Choi SH, Byun Y, Lee G. Expressions of uroplakins in the mouse urinary bladder with cyclophosphamide-induced cystitis. J Korean Med Sci 2009;24:684-9.

44. Kyung YS, Park HY, Lee G. Preservation of uroplakins by 2-mercaptoethanesulfonate in cyclophosphamide-induced rat cystitis. Arch Toxicol 2011;85:51-7. 